\title{
Íleo biliar en paciente de edad avanzada
}

\author{
R. Pozo Moreno, M. Rojas Feria, H. Pallares Manrique, M. Ramos Lora y A. Domínguez Macías
}

Servicio de Aparato Digestivo. Hospital Juan Ramón Jiménez. Huelva

Presentamos el caso de un varón de 87 años con antecedentes de hipertensión arterial, dislipemia y Alzheimer incipiente. Acude a urgencias por dolor en hemiabdomen superior e hipocondrio derecho de 72 horas de evolución, acompañado de cuadro emético de escasa cuantía (contenido de aspecto oscuro) y de estreñimiento de 4 días. En la exploración física presentaba un aceptable estado general, estando afebril, normotenso y con auscultación cardiorrespiratoria dentro de la normalidad. El abdomen era blando, depresible, doloroso en hipocondrio derecho a la palpación profunda, con ruidos metálicos, sin masas ni megalias, no Murphy. No presentaba semiología de trombosis venosa profunda ni edemas en miembros inferiores.

Analíticamente destacaba normalidad de todos sus parámetros, incluyendo hemograma, coagulación, bioquímica general con perfil abdominal y gasometría venosa. En la radiografía de abdomen en bipedestación a su ingreso (Fig. 1) se apreciaba una ligera dilatación de cavidad gástrica con una imagen redondeada de unos 2-3 cm de densidad calcio en hipocondrio derecho.

El paciente se ingresó en el Servicio de Aparato Digestivo instaurándose reposo intestinal, analgesia y sonda nasogástrica conectada a bolsa (débito marronáceo, fétido y líquido). A las 24 horas se objetivó disminución significativa del dolor en hipocondrio derecho y aparición de dolor en región periumbilical de características cólicas, con silencio abdominal e imposibilidad para la expulsión de gas y heces. Ante la sospecha de un cuadro de obstrucción intestinal se realizó una segunda radiografía de abdomen en bipedestación (Fig. 2), en la que se observó aerobilia, dilatación de la cavidad gástrica y de prácticamente todo el intestino delgado y una imagen hiperdensa de densidad calcio de unos 2,5 cm proyectada sobre la pala iliaca derecha.

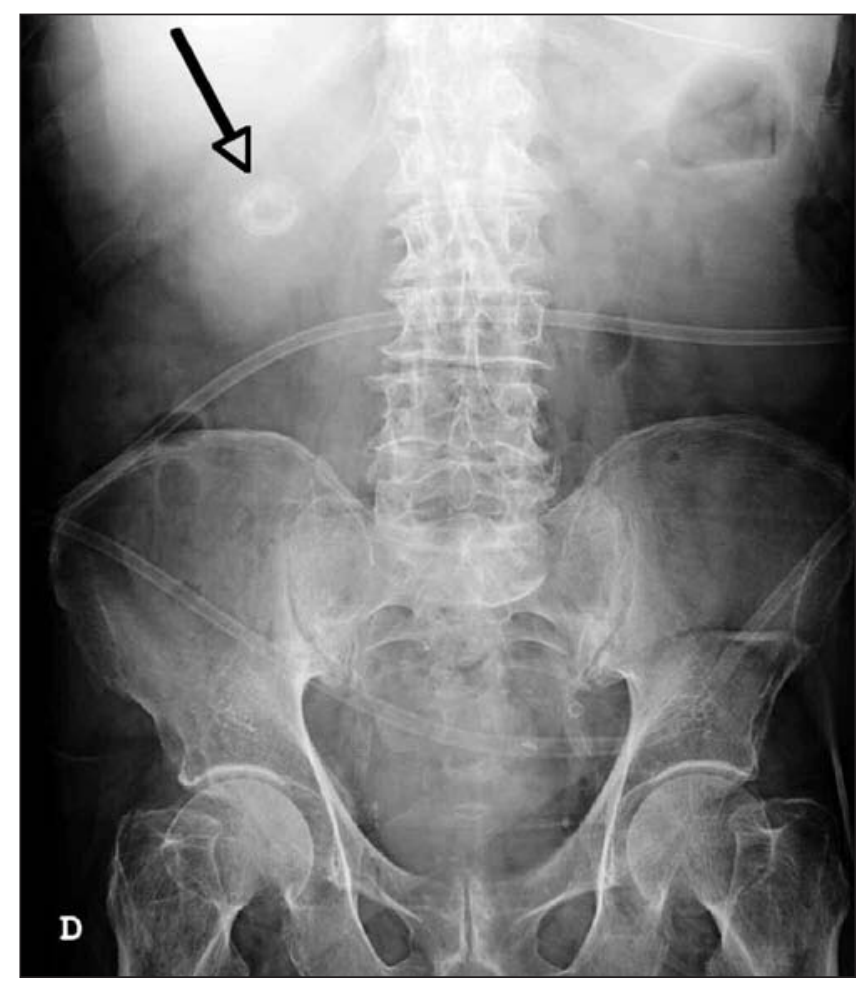

Fig. 1. (Al ingreso). Imagen densidad calcio en hipocondrio derecho.

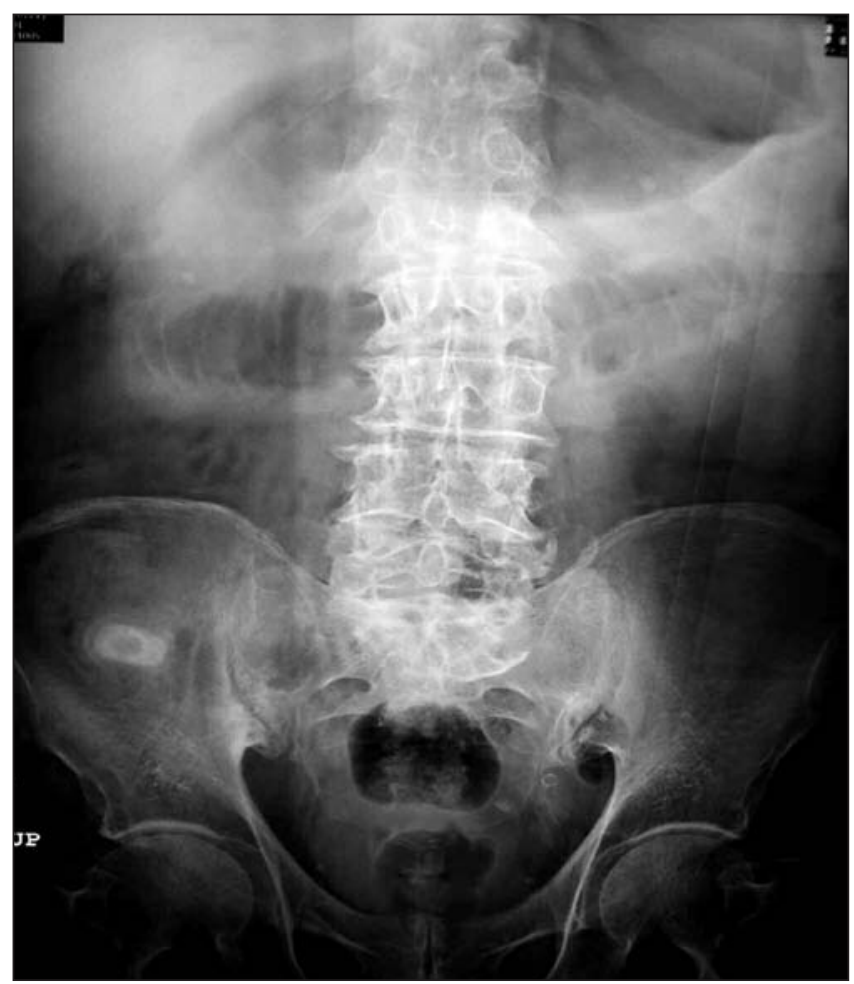

Fig. 2. (A las 48 horas). Imagen densidad calcio fosa iliaca derecha. 
Ante el cuadro de obstrucción intestinal secundario a íleo biliar se intervino quirúrgicamente, realizándose una enterotomía y extracción del cálculo con posterior enteroplastia, evolucionando satisfactoriamente tras la misma.

El íleo biliar es causa infrecuente de obstrucción intestinal, responsable de alrededor del 1 al $4 \%$ de los casos $(1,2)$. Representa una obstrucción mecánica verdadera del intestino debido a un cálculo de más de $2 \mathrm{~cm}$ aproximadamente o varios que obstruyen la luz del mismo, siendo el lugar más frecuente el íleon (60\%). Lo más característico es que haya una fístula colecistoduodenal por donde pasa el cálculo al intestino y en ocasiones si el cálculo es pequeño atraviesa la ampolla de Vater. Siendo diagnosticado principalmente por la clínica de obstrucción intestinal y técnicas de imagen (radiografía, $\mathrm{TAC}, . .$.$) , el tratamiento es quirúrgico, como se realizó en nuestro paciente (3).$

\section{BIBLIOGRAFÍA}

1. Lobo DL, Jobling JC, Balfour JW. Gallstone ileus: Diagnostic pitfalls and therapeutic successes. J Clin Gastroenterol $2000 ; 30$ : 72.

2. Clavien PA, Richon J, Burgan S, et al. Gallstone ileus. Br J Surg 1990; 77: 737.

3. Reisner RM, Cohen JR. Gallstone ileus: A review of 1001 reported cases. Am Surg 1994; 60: 441. 